\title{
Seeking the Roots of Entrepreneurship: Insights from Behavioral Economics
}

\section{Citation}

Astebro, Thomas, Holger Herz, Ramana Nanda, and Roberto A. Weber. "Seeking the Roots of Entrepreneurship: Insights from Behavioral Economics." Journal of Economic Perspectives 28, no. 3 (Summer 2014): 49-70.

\section{Published Version}

https://www.aeaweb.org/articles?id=10.1257/jep.28.3.49

\section{Permanent link}

http://nrs.harvard.edu/urn-3:HUL.InstRepos:41845081

\section{Terms of Use}

This article was downloaded from Harvard University's DASH repository, and is made available under the terms and conditions applicable to Other Posted Material, as set forth at http:// nrs.harvard.edu/urn-3:HUL.InstRepos:dash.current.terms-of-use\#LAA

\section{Share Your Story}

The Harvard community has made this article openly available.

Please share how this access benefits you. Submit a story.

\section{Accessibility}




\title{
Seeking the Roots of Entrepreneurship: Insights from Behavioral Economics ${ }^{\dagger}$
}

\author{
Thomas Åstebro, Holger Herz, Ramana Nanda, \\ and Roberto A. Weber
}

$\mathbf{F}$ rank Knight (1921) proposed that we should not think of entrepreneurship as simply investment under risk, where decisions are made with respect to an objectively known distribution of returns. He argued that entrepreneurship in such a world would not require any particular skill and it would be inconceivable that entrepreneurs could earn rents simply for bearing objective risk as a market should eliminate those rents. Knight therefore put forward the idea that the prerequisites for entrepreneurial activity are a combination of highly uncertain returns that do not have an objectively known distribution, as well as the entrepreneur's skill in perceiving opportunity more clearly than others.

Knight's (1921) work focused attention on the specific individuals pursuing entrepreneurship and what made them distinct. Subsequent research in this vein has aimed to understand the individual traits, motivations, and preferences that make some individuals more likely to pursue entrepreneurship than others. Ironically, while Knight was interested in justifying why entrepreneurs should earn supernormal returns, much of this subsequent research has found the opposite to be true. That is, there is a growing body of evidence that many entrepreneurs seem

- Thomas Astebro is Associate Professor of Strategy and Entrepreneurship, HEC Paris, Paris, France. Holger Herz holds a senior research associate position in Microeconomics and Experimental Economic Research, University of Zurich. Zurich, Switzerland. Ramana Nanda is Associate Professor of Business Administration, Harvard Business School, Boston, Massachusetts, and a Faculty Research Fellow at the National Bureau of Economic Research, Cambridge, Massachusetts. Roberto A. Weber is Professor of Economics, University of Zurich, Zurich, Switzerland. Their email addresses are astebro@hec.fr, holger.herz@econ.uzh.ch, RNanda@hbs.edu, and roberto.weber@econ.uzh.ch.

${ }^{\dagger}$ To access the data Appendix and disclosure statements, visit http://dx.doi.org/10.1257/jep.28.3.49

doi $=10.1257 /$ jep.28.3.49 
to enter and persist in entrepreneurship despite earning low risk-adjusted returns. This finding has led, in turn, to attempts to provide explanations-using both standard economic theory and behavioral economics-for why certain individuals may be attracted to such an apparently unprofitable activity.

In this article, we critically evaluate what the existing research shows regarding the individual determinants of entrepreneurship. We begin by documenting a set of facts that seem to pose a challenge for interpretations of entrepreneurship based on the standard expected utility framework. The expected returns to entrepreneurship tend to be low on average but exhibit a high variance due to the fact that most startups fail completely and only a few are extremely successful. Hall and Woodward (2010) calculate that, for normal degrees of risk aversion, the very low probability of success and high probability of zero exit value make the expected utility of entrepreneurial ventures negative-meaning that people should prefer not to engage in entrepreneurship. Yet each year, over 500,000 individuals in the United States start firms with at least one employee, and approximately 40 percent of American workers experience at least one period of self-employment during their careers (Parker 2009). Entrepreneurs also seem to persist in running businesses for long periods of time despite either low absolute returns (Hamilton 2000; Åstebro 2003) or returns that appear low after controlling for the highly concentrated illiquid stakes they hold in businesses compared to public equity markets (Moskowitz and Vissing-Jørgensen 2002).

The fact that individuals enter and persist in entrepreneurship despite low risk-adjusted returns suggests that standard theories of risk and return provide an incomplete basis for entrepreneurship and may need to be complemented with richer foundations. That is, while it certainly seems plausible that entrepreneurs have different preferences about risk in a broad sense, there is also the possibility that the standard expected utility model based on objectively known distributions of risk may not capture such differences well. Indeed, widely held popular interpretations of entrepreneurial entry often appeal to behavioral explanations, such as those involving high degrees of risk loving among entrepreneurs who "don't need to be rewarded for risk, because they actually get utility out of risk itself" (Harrington 2010); overconfidence and "endemic optimism" in the startup world (Surowiecki 2014); or entrepreneurs who forgo pecuniary rewards because of the genuine pleasure they obtain from creating and controlling a business (Wasserman 2008).

Drawing on research in behavioral economics, in the sections that follow, we review three sets of possible interpretations for understanding the empirical facts related to the entry into, and persistence in, entrepreneurship. Differences in risk aversion provide a plausible and intuitive interpretation of entrepreneurial activity. In addition, a growing literature has begun to highlight the potential importance of overconfidence in driving entrepreneurial outcomes. Such a mechanism may appear at face value to work like a lower level of risk aversion, but there are clear conceptual differences-in particular, overconfidence likely arises from behavioral biases and misperceptions of probability distributions. Finally, nonpecuniary, 
taste-based factors may be important in motivating both the decisions to enter into and to persist in entrepreneurship.

While all these candidate explanations have merit and can account for some aspects of the facts above, there is little evidence of a "smoking gun" that can completely account for all the puzzling patterns we observe. In fact, our reading of the literature suggests that even papers that find evidence consistent with one interpretation are often unable to rule out other mechanisms that are also consistent with their results. Hence, while strong statements on what drives entrepreneurs are widespread in the popular literature, the evidence thus far fails to provide compelling evidence for such a unifying interpretation. Indeed, it is unclear whether a single interpretation that can account for the entire puzzle of entrepreneurial behavior even exists.

A deeper understanding of the roots of entrepreneurship is not only important from a theoretical and academic standpoint, but is also critical for policies addressing entrepreneurship, given the central role that entrepreneurs play in driving productivity growth. In particular, distinguishing the extent to which these patterns are driven by behavioral biases versus preferences is important when thinking about policies that might promote entrepreneurship. Therefore, after reviewing the evidence regarding interpretations for the empirical puzzle, we outline promising avenues for further research.

\section{The Entrepreneur's Risk and Return: An Empirical Puzzle}

We begin with a set of empirical patterns related to entrepreneurship that create a puzzle when seen through the lens of standard economic models of expected utility and risk.

First, the empirical evidence on returns to entrepreneurship suggests that it tends to be an activity with low median returns but with very high variance-that is, a few entrepreneurs are extremely successful, but the vast majority of entrepreneurs either fail or face meager returns. Figure 1 documents these patterns, both for the broader economy and for the subset of new ventures that are backed by venture capital. Figure 1A is based on data from the Business Information Tracking Series at the US Census Bureau, as documented by Shane (2009). For the 510,654 businesses founded in 1996, Shane (2009) calculates the share of businesses that had either failed or achieved a certain level of annual sales six years later in 2002. Over 50 percent of the businesses had failed within the six years, less than 10 percent achieved more than $\$ 1$ million in sales, and less than 1 percent had achieved more than $\$ 10$ million in sales. However, 175 firms or 0.03 percent achieved more than $\$ 100$ million in sales, making them extremely valuable (and rare) business endeavors. These failure rates are broadly consistent with Kerr and Nanda (2010), who document that 50 percent of all startups founded in the United States between 1976 and 2001 exited within the first four years following entry and 70 percent failed by their tenth year, suggesting there was nothing particularly different about startups founded in 1996. 
Figure 1

The Pattern of Failure and Success in Entrepreneurship

A: Sales in 2002 for 510,654 Firms Founded in the United States in 1996

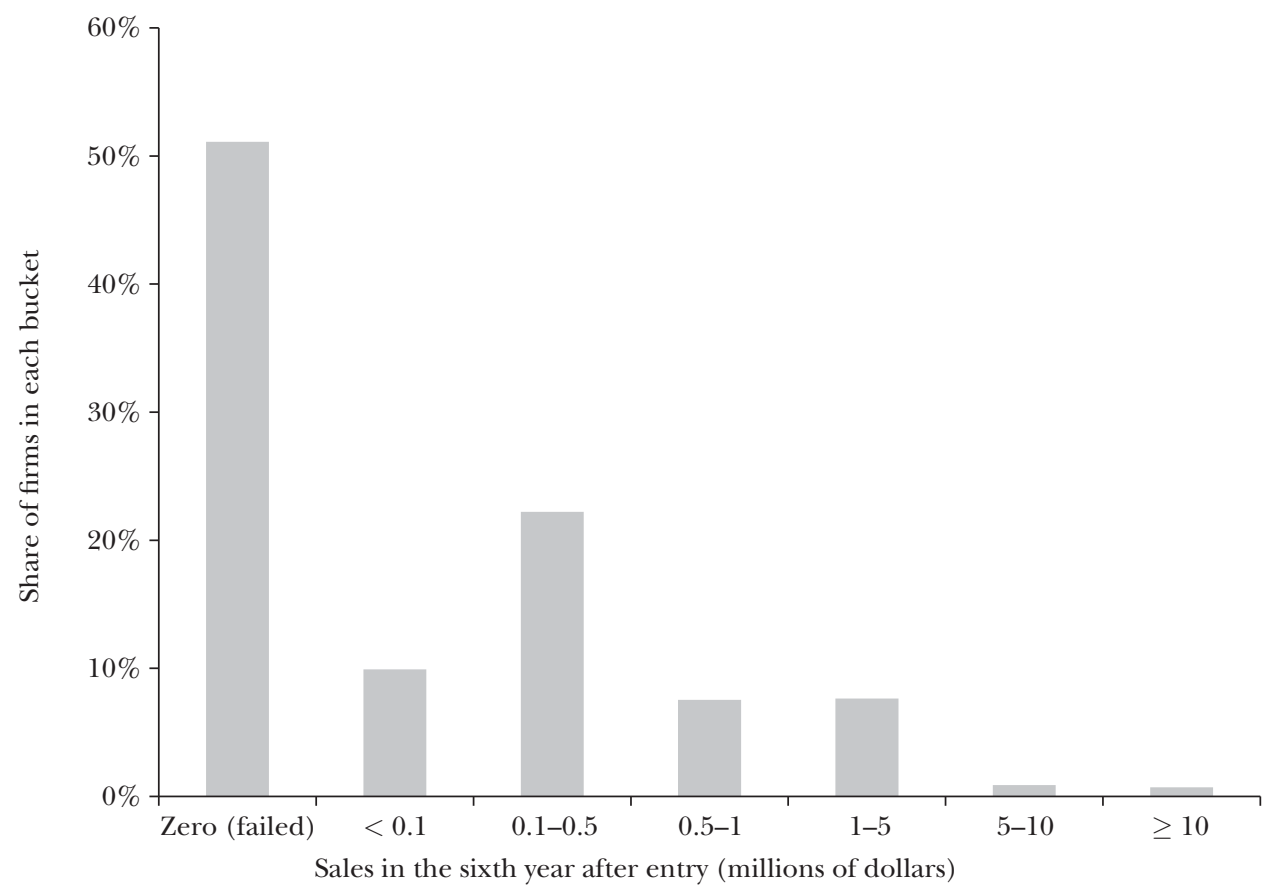

Source: Figure 1A is based on data from the Business Information Tracking Series at the US Census Bureau, as documented by Shane (2009).

Note: Figure 1A shows for the 510,654 US businesses founded in 1996, the share that had either failed or achieved a certain level of sales by 2002.

Figure 1B is based on data from Sand Hill Econometrics, as reported by Hall and Woodward (2010). They analyze the outcomes at exit for the subset of startups founded between 1987 and 2008 in the United States that were financed by venture capital. Venture-capital-backed startups account for under 1 percent of the startups founded each year and typically focus on higher-growth ventures commercializing new technologies or products. The typical contract between the venture capital investor and the entrepreneur involves the entrepreneur taking a below-market salary and a share of the equity. Hall and Woodward find that even for these high-growth ventures, the equity value is zero in almost three-quarters of the startups in their sample. However, a few "billion dollar exits" raise the average value of the entrepreneurs' equity to $\$ 5.8$ million. Hall and Woodward calculate that, for normal degrees of risk aversion, the very low probability of success and high probability of zero exit value combined with the below market salary makes the expected utility of entrepreneurial ventures presumptively negative-meaning that people should prefer not to engage in entrepreneurship. Because the same 


\section{Figure 1 (continued)}

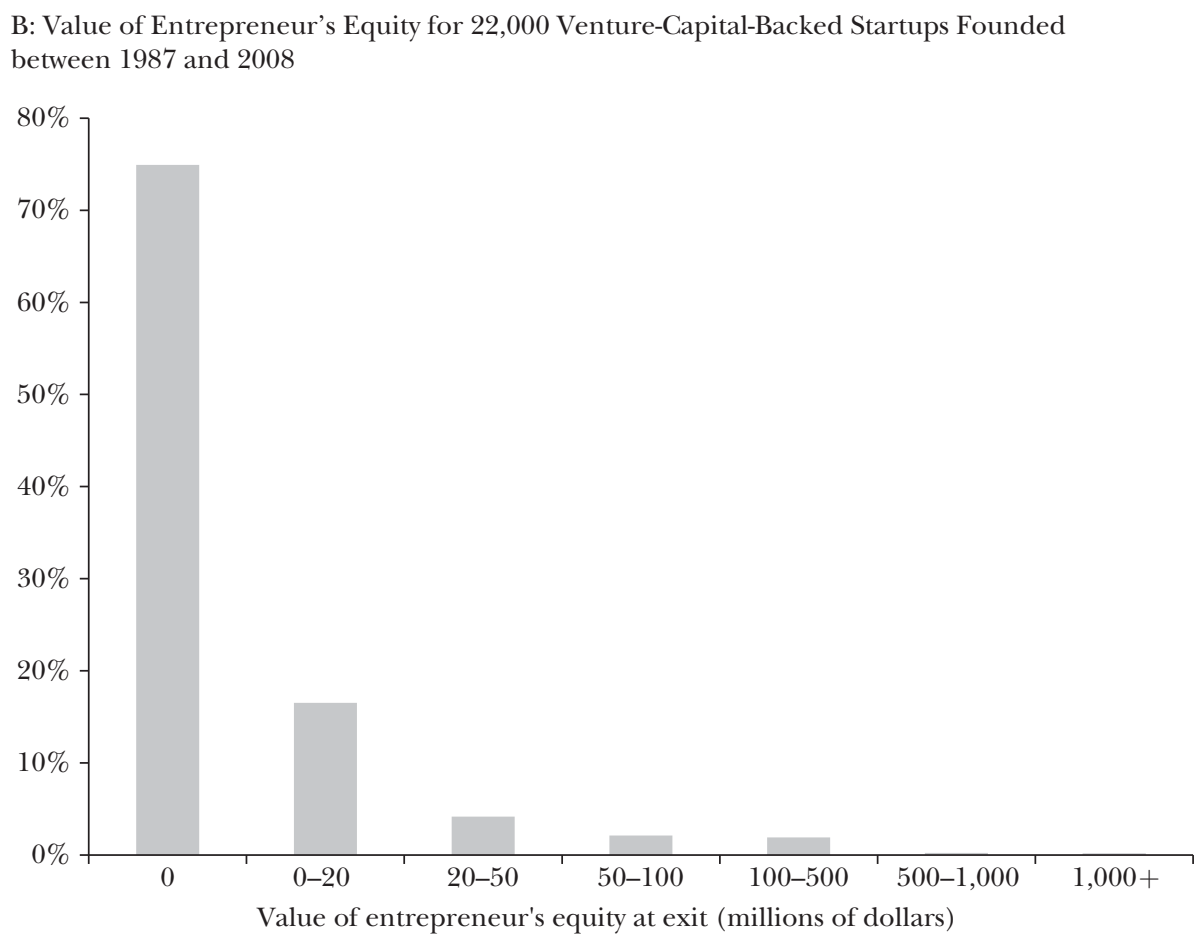

Source: Figure 1B is based on data from Sand Hill Econometrics, as reported by Hall and Woodward (2010). Note: Figure 1B analyzes outcomes at exit for the subset of startups in the US founded between 1987 and 2008 that were financed by venture capital.

skewed distributions of returns are present for all startups in the United States, and these startups are likely to yield much lower returns than the venture-capital-backed startups, this suggests that Hall and Woodward's (2010) conclusion that people with a normal degree of risk aversion should not become entrepreneurs applies not only to venture-capital-backed entrepreneurial activity, but to entrepreneurial activity more generally.

The expected utility framework does, of course, allow for heterogeneous risk preferences. However, these patterns, when combined with the high frequency of participation in entrepreneurship, suggest that either a sizeable proportion of the population is risk-loving (making it hard to reconcile with other facts about decision making in the general population), or the expected utility framework does not provide a complete characterization of how individuals decide whether to pursue entrepreneurship.

A second dimension of the entrepreneurial puzzle is that not only do many individuals enter despite such low odds of success, but entrepreneurs also seem to persist in running businesses for long periods of time despite either low absolute 
returns (Hamilton 2000) or returns that appear low after controlling for the highly concentrated illiquid stakes they hold in businesses compared to public equity markets. For example, Moskowitz and Vissing-Jørgensen (2002) find that entrepreneurial households persistently hold large undiversified stakes in their (mostly private) firms, whose returns are no greater than that of public equity. They find that these "private equity" investments are at least as volatile and far less liquid than public equity markets, but the returns to these highly undiversified entrepreneurial private equity portfolios are no higher than the returns to public equity. They conclude that the private equity should require a premium of at least 10 percent per year to justify such investment. Furthermore, Åstebro, Jeffrey, and Adomdza (2007) found, using a sample of 820 Canadian inventor entrepreneurs who had sought and paid for assistance from a center originating from the University of Waterloo, that almost one-third continued to spend money and half continued to spend time on projects even after the diagnostic advice from the center advised them to cease; and follow-up data showed little to no value from their further efforts.

Corroborating evidence of this puzzle is provided in Figure 2. which compares the total earnings of wage employees to those of self-employed individuals, using comprehensive microdata from Denmark. The analysis is based on a 10-percent random sample of all employees and entrepreneurs in 1995, but is then conditioned on individuals whose tenure at their job is at least ten years-in order to compare individuals who would be presumed to have a good match to their job. Similar to Figure 1, Figure 2 documents very high dispersion of earnings among the self-employed, including a large number of individuals whose earnings are lower than that of the typical wage employee. Figure 2 is based on individuals who have been in their job for at least ten years, meaning that this pattern cannot be accounted for purely by lack of time for some entrepreneurs to learn they have low ability and exit (as in Jovanovic 1982). It's true that the comparison in Figure 2 does not control for observable covariates across these groups, and it does not account for sorting based on comparative advantage: thus, it is possible that some of the self-employed who earn less than wage employees are earning the most that they could in either sector. However, Hamilton (2000) finds that, in his sample based on US data, the patterns hold true even when accounting for covariates and for sorting based on sector-specific abilities. The pattern illustrated in Figure 2 seems to suggest the presence of compensating differentials, where some entrepreneurs seem willing to persistently take lower earnings in return for the nonpecuniary benefits associated with self-employment.

\section{Understanding Entrepreneurial Decision Making}

\section{Risk Preferences}

In the standard expected utility framework, the expected returns to entrepreneurship are determined by the probability distribution over various possible outcomes and the utility obtained from the monetary returns in each of these 
Figure 2

\section{Comparison of Wage versus Self-Employment Earnings (Denmark)}

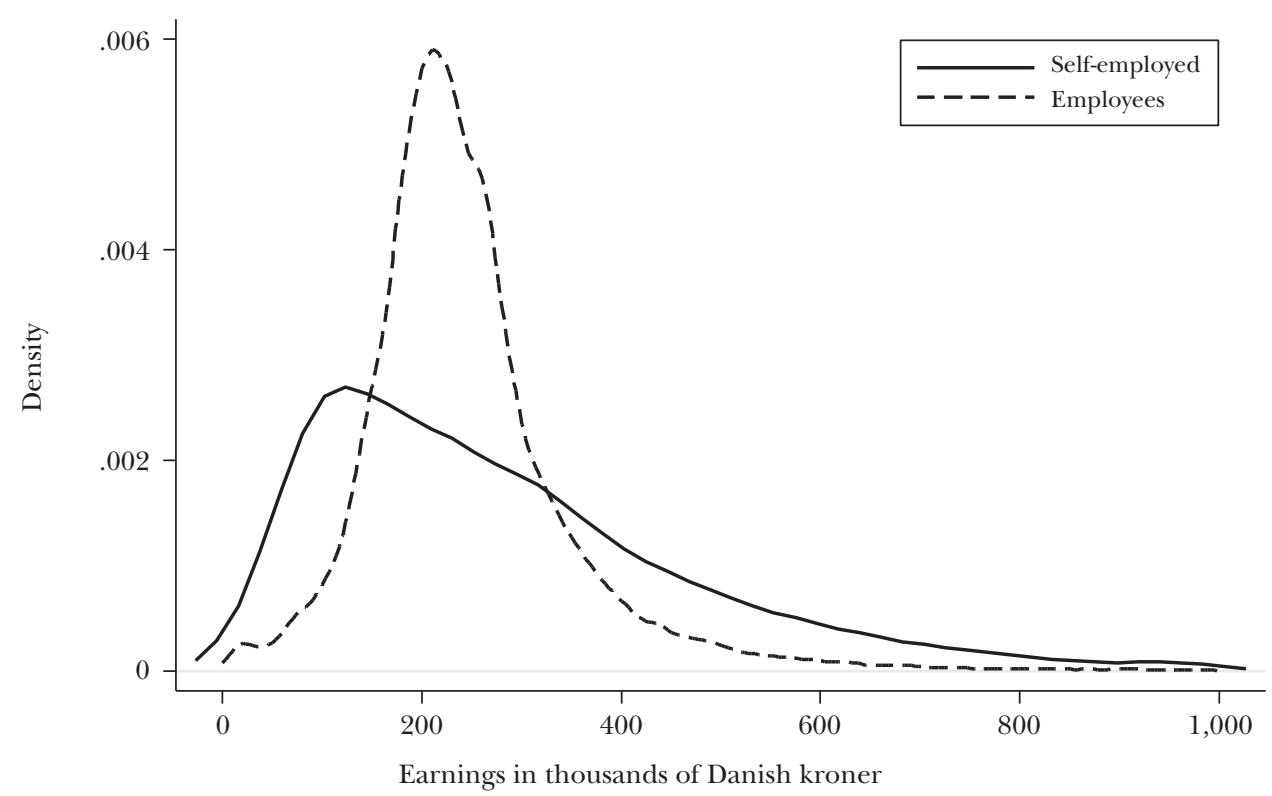

Source: Authors using data from the Integrated Database for Labor Market Research (IDA). The database is maintained by the Danish government and consists of an annual panel of all individuals, and firms in Denmark.

Notes: Figure 2 compares the total earnings of wage employees to those of self-employed individuals, using comprehensive microdata from Denmark. The distributions are truncated at 1 million Danish kroner. See text for details.

outcomes. An individual will enter entrepreneurship if this utility assessment is preferable to some alternative occupation, and choose employment otherwise.

Risk preferences are defined by the utility function over wealth in the standard expected utility framework. Most people have utility functions that imply risk aversion, and such people are more willing to take work with regular and less-variable pay. However, a smaller proportion of people-who exhibit less curvature in their utility functions over wealth, and thus less risk aversion-are more likely to be attracted to the possibility of large gains from highly risky ventures such as entrepreneurial activity. Thus, holding constant other factors such as entrepreneurial ability and financing constraints, the individual's preferences over risk can play a critical role in determining the entry decision.

Early models of entrepreneurship attempted to account for entrepreneurial entry within the standard expected-utility framework of economic decision making under risk. For instance, Kihlstrom and Laffont (1979) proposed a theory of entrepreneurship based on differences in risk attitudes, in which optimal risk-sharing between individuals implies that those who are more risk-tolerant become entrepreneurs, while those who are more risk-averse become employees. 
A number of empirical studies have attempted to document a difference in risk preferences between entrepreneurs and similar workers who do not start businesses, but the results have been mixed. One approach involves measuring risk taking in other domains of life and using these observations as a proxy for an individual's risk tolerance. Hvide and Panos (2014) look at detailed data on Norwegians who started firms from 2000-2007. They rely on extensive Norwegian government data from tax records that include investment behavior and wealth, as well as on detailed records of all new incorporations in the relevant time period. They show that individuals who participate in the stock market, who invest a higher fraction of their wealth into the stock market, or who have more volatile stock portfolios-presumably, those who possess greater risk tolerance-are more likely to become entrepreneurs. Moreover, Hvide and Panos also find that more risk-tolerant entrepreneurs yield lower-performing firms, measured by number of employees, sales, and profitability. This is consistent with the theoretical prediction that individuals with higher tolerance for risk are willing to enter entrepreneurship in expectation of lower returns, keeping the risk constant.

Another approach to documenting a connection between risk preferences and entrepreneurial entry is to attempt to measure individuals' risk preferences directly. Parker (2009) provides a review of studies comparing such measures between entrepreneur and non-entrepreneur samples. However, no clear picture arises, with some studies pointing toward differences in risk attitudes between the two samples, while others find no such relationship between risk attitudes and entrepreneurship. Many of these studies suffer from small samples and non-incentivized methods of eliciting risk preferences. There also exists the possibility that the samples, often the product of convenience and access, are nonrepresentative of the broader populations of entrepreneurs and non-entrepreneurs.

Other studies use longitudinal data to compare risk attitudes earlier in life with later career paths. Ahn (2010) looks at responses to hypothetical questions about risk that were included in 1993 and in 2002 in the 1979 National Longitudinal Survey of Youth and finds that those who indicate less risk aversion are more likely to become entrepreneurs in the subsequent two years. Cramer, Hartog, Jonker, and Van Praag (2002) use the "Brabant survey" that involved 5,800 Dutch schoolchildren who were originally interviewed and tested in 1952 at the age of 12 . In a re-interview in 1993, 1,800 of the original participants answered a hypothetical risk question, and those who had been self-employed at some point in time in the observation period indicated lower degrees of risk aversion. While these studies add value because of their longitudinal nature, they still suffer from the hypothetical nature of the risk elicitation method, and in some instances, the risk measures taken later in life may not match risk preferences at the earlier stage of life.

Further promise for identifying risk attitudes as a driver of entrepreneurial entry comes from experimental economics, which offers tools for incentivized elicitation of individuals' risk preferences. Individuals are confronted with choices between lotteries and certain payments, with real financial consequences, and their profile of choices provides a direct measure of their risk preferences (Holt and 
Laury 2002). If risk preferences constitute a stable characteristic of an individual, and these preferences drive entrepreneurship, the application of such methods to eliciting risk preferences for samples of entrepreneurs and non-entrepreneurs could provide evidence that these groups differ in their risk preferences. One study attempting to create such a connection was conducted by Holm, Opper, and Nee (2013). They randomly sampled 700 entrepreneurs heading firms with at least ten employees from local firm registers and 200 control subjects from the Yangzi delta region of China. Both were offered the same incentivized choice menu between various risky and safe outcomes. However, the answers show no difference in preferences towards risk between the entrepreneurs and the control group. When choice menus were offered that involved ambiguity rather than objective risk, the result was the same-again, no difference was found between entrepreneurs and the control group.

In short, the evidence that entrepreneurial entry can be explained by a group of people with very different general risk attitudes than the general population is quite mixed and inconclusive. Some studies suggest that those who start firms are more risk seeking, but others find no association. Indeed, perhaps the most compelling tests from the viewpoint of a critical economist-those in which incentivized elicitation of risk preferences is employed-do not find strong evidence of such entrepreneur versus non-entrepreneur heterogeneity.

Hence, while an interpretation of entrepreneurship as reflecting lower degrees of risk aversion than those in the population remains a potential parsimonious interpretation for some aspects of the puzzle, more evidence is needed before one can conclude that lower risk aversion is, indeed, a primary driver. The evidence on whether entrepreneurs are less risk-averse and whether this preference drives entrepreneurial entry decisions remains, at best, suggestive. Moreover, even if entrepreneurs are less risk-averse than the general population, this finding would not directly imply that entrepreneurs are willing to take the relatively high degrees of risk associated with entrepreneurial entry.

\section{Overconfidence}

An alternative explanation that is often proposed to explain entry into entrepreneurship is overconfidence. This explanation implies that individuals enter into entrepreneurship because they subjectively perceive the return distribution too favorably when evaluating their own entrepreneurial project. For example, Cooper, Woo, and Dunkelberg (1988) report that 33 percent of the 3,000 entrepreneurs they surveyed put their odds of success at 10 out of 10 , despite putting much lower odds of success for other businesses that were similar to their own. More recently, Shane (2009) reports findings from a Global Entrepreneurship Monitor survey that finds US entrepreneurs report believing it more than five times as likely that they will have at least $\$ 10$ million in sales than is empirically the case. It has therefore been suggested that those seeking to become entrepreneurs must be imbued with what Adam Smith (1776 [1904], p. 110; see also de Meza and Southey 1996, p. 375) termed "the contempt of risk and the presumptuous hope of success." 
Overconfidence may even account for differential patterns of behavior among those who become entrepreneurs. Landier and Thesmar (2009) used survey data collected by Statistics France on a nationally representative sample of French entrepreneurs to construct a measure comparing expectations with future outcomes, which were measured using linked panel data. Those whose expectations exceeded future outcomes were more likely to use short-term debt finance rather than the less-risky option of long-term debt finance.

People often use the general term "overconfidence" to interpret results like those above. However, multiple measures and definitions across empirical studies have made it hard to pin down the precise bias that may be behind entrepreneurship. Moore and Healy (2008) provide a useful distinction between three forms of the general phenomenon of overconfidence. The first concept is overestimation of one's ability or performance. The second concept is overplacement: individuals assess their skill relative to others as too high. Finally, overprecision is the excessive certainty regarding the accuracy of one's beliefs. In addition, one needs to distinguish overconfidence from optimism (Weinstein 1980), which reflects a general view that "good things will happen." Optimism is considered to be a more stable individual trait, not specific to a particular project; to be optimistic is to have generally positively biased expectations. Economists more precisely define an optimist as a person who generally "revises up the probability of favorable events and revises down the probability of unfavorable events" (Hey 1984).

Overestimation, overplacement, and optimism are often observationally equivalent-for example, the above survey evidence from 3,000 entrepreneurs by Cooper, Woo, and Dunkelberg (1988) cannot distinguish between them. However, the underlying psychology is quite different, and the decision environment determines which factors can actually be at work. For example, overplacement requires direct comparisons to a reference group, a feature mainly present in established and contested markets; overestimation applies more broadly to a larger set of situations in which individuals judge their own ability; and optimism indicates a general belief propensity that applies even to situations over which a decision maker has no control. Consequently, the implications of these mechanisms for understanding entrepreneurship and for policy may not be equivalent. Therefore, an understanding of the precise form of overconfidence that might account for the puzzle of excessive entrepreneurial entry requires an ability to distinguish which precise bias drives entrepreneurship, and under what circumstances.

Optimism and overestimation. Researchers have tried to establish a relationship between general optimism and entrepreneurship by measuring optimism in domains of life unrelated to an individual's entrepreneurial skills. Puri and Robinson (2007) constructed such a measure based on data from the Survey of Consumer Finance: specifically, they compared people's own estimates of their life expectancy to what is implied by actuarial tables. They found that more-optimistic people were more likely to be entrepreneurs. They also found that extreme optimists were more likely to make high-risk and even imprudent financial choices. Relatedly, Bengtsson and Ekeblom (2014) use survey data on Swedes' beliefs about 
future nationwide economic conditions using responses from 153 monthly surveys conducted between January 1996 and October 2009, again measuring optimism by how expressed beliefs relate to later outcomes. They find that entrepreneurs hold more optimistic beliefs about the general economy, but also that they have lower forecast errors than non-entrepreneurs.

Dawson, de Meza, Henley, and Arabsheibani (2014) used the British Household Panel Study covering 1991-2008 to examine how optimistic forecasts-comparing earnings expectations with future realized outcomes as an employee-predicted performance in subsequent entrepreneurship spells. Since the authors had multiple years of data for individuals as wage earners (on average 5.1 years) they could construct individual fixed-effects estimates of prior optimism net of any environmental influences. The authors also carefully excluded effects from individual ability, which could otherwise co-determine both prior wage earnings-and thus the authors' measure of optimism-and future earnings as an entrepreneur. Dawson et al. found that optimists, on average, earned less than pessimists in entrepreneurship, and that the earnings difference was largest at the top of the earnings distribution and not significant at the bottom.

While optimism and overestimation are often closely related, some work attempts to explicitly differentiate between the two as drivers of entrepreneurial entry. Åstebro, Jeffrey, and Adomdza (2007) compared the behavior of 820 Canadian inventor-entrepreneurs, measuring both overestimation and optimism, with that of a comparable random sample of 300 Canadian citizens. The authors followed a well-established method for measuring overestimation by comparing individuals' predictions of their performance to their actual performances on a general knowledge test (Lichtenstein, Fischoff, and Phillips 1982). In addition, the authors measured optimism as reflecting a person's general view that good things will happen (Weinstein 1980). The survey data showed that inventors tended toward both more overestimation and optimism than the comparison group. However, the overestimation measure was not significantly related to increased expenditures of time and money, while entrepreneurs with greater levels of optimism were more likely to keep pursuing an idea even with little chance of success, and thus to incur higher losses.

The controlled decision environments provided by incentivized experiments make them useful to further assess the relevance of overestimation and optimism. Studying the behavior of students and executives with entrepreneurial experience in laboratory experiments, Åstebro, Mata, and Santos-Pinto (2014) employed an experimental design in which success probabilities are exogenously determined and known by subjects, in order to rule out overestimation of own skill as a driver of behavior. Their findings suggest that general optimism, rather than convex utility, drives what appears to be a preference for the kinds of skewed lotteries that characterize entrepreneurship.

Overplacement. Overplacement is different from overestimation and optimism in that it refers to a direct comparison of own skill to competitors. Consequently, overplacement may be a particularly valid explanation for entrepreneurial entry into contested markets, where one could have a biased belief in the likelihood of 
coming out ahead of the competition. Early evidence suggesting such a relationship between overplacement and market entry came from an experiment by Camerer and Lovallo (1999). In their experiment, students who were undergraduates or MBAs at either the University of Chicago or the University of Pennsylvania could earn money by entering a "market" where payoffs depend on their rank among all entrants. In the baseline condition, ranks were assigned randomly, but in a skill condition, subjects were told they would be ranked according to their relative performance in a trivia quiz. Camerer and Lovallo found that significantly more subjects entered the market in the skill condition. This excessive entry took place despite the fact that subjects correctly predicted that there would be excessive entry in the skill condition (but not in the baseline condition). The authors concluded that although subjects expect excessive entry, they are willing to enter the market because they hold a biased belief that they are among the most skilled, which makes entry appear profitable in expectation.

The study by Holm, Opper, and Nee (2013) of Chinese entrepreneurs and control subjects discussed in the previous section also provides evidence suggesting a possible relationship between overplacement and entrepreneurial market entry. Their entrepreneur and control subjects participated in a market entry task similar to the one used by Camerer and Lovallo (1999). Holm et al. find that the entrepreneurs were more willing to enter competitive environments, in which success depended on own skill, than the control group. However, the entrepreneurs did not, on average, overplace themselves in expected performance compared to the control group. Hence, the connection between overplacement and entrepreneurship in this study is imperfect and raises the possibility that the entrepreneurs possess a preference for competition per se, rather than biased beliefs about their relative abilities.

Overprecision. While overplacement, overestimation, and optimism all lead to positively biased perceptions of expected returns and hence should foster entrepreneurial entry, the effects of overprecision are less clear. Herz, Schunk, and Zehnder (2014) look at the effect of overprecision on the trade-off between exploration and exploitation, one of the key features of the innovative process that also underlies entrepreneurial activity (Kerr, Nanda, and Rhodes-Kropf, in this symposium). They argue that overprecision, the tendency to underestimate variance of own information, can reduce the perceived option value of exploration and therefore actually reduce incentives to engage in entrepreneurship. Herz, Schunk, and Zehnder experimentally tested these predictions with students and business managers. Subjects participated in an incentivized individual decision-making task in which they had to manage a virtual ice cream stand and repeatedly make decisions over the offered product mix. ${ }^{1}$ Subjects faced an overall choice about tweaking a preexisting strategy or trying brand-new strategies to maximize profits. Overprecision was then measured in an independent task using an established method in which

\footnotetext{
${ }^{1}$ The experiment is adopted from Ederer and Manso (2013), who use a similar task to study the effect of different incentive schemes on the exploration-exploitation trade-off.
} 
individuals state 90 percent confidence intervals for ten trivia questions-that is, such that they are 90 percent certain that the correct answer is contained in the interval (Lichtenstein et al. 1982). Subjects who are overconfident in precision typically provide overly narrow ranges, so that actual values fall outside the range more than 10 percent of the time. Herz, Schunk, and Zehnder find that overprecision is indeed negatively related to experimentation and realized profits, suggesting the possibility that some forms of overconfidence may lead to a bias away from the type of exploration that is central to entrepreneurship.

Taken together, some evidence suggests overconfidence in the form of optimism, overestimation, and overplacement could help explain entrepreneurial entry. Perhaps the strongest support comes from correlational evidence between broad measures of optimism and entrepreneurship. However, even if one believes these correlations reflect a causal relationship, the precise nature of overconfidence driving the relationship is not well understood. Since different forms of overconfidence may differentially impact entrepreneurial decision making, more work is required to better understand the precise type of overconfidence that affects entrepreneurship and how it does so.

Moreover, many open questions remain. For starters, the studies above measure overconfidence using measures unrelated to the domain of entrepreneurship; that is, measures of overconfidence and optimism mostly stem from independent measurements, assuming that these are personality traits that apply generally. This assumption may have some merit, but it would be valuable to have more detailed measures of different forms of overconfidence and optimism directly relating to entrepreneurial activity. For example, in contexts other than entrepreneurial entry, some headway has been made in this direction by Malmendier and Tate (2005a; 2005b) by measuring chief executive officers' overconfidence as continuing to hold stock options in their own firms after the options are fully vested.

Finally, several researchers note that behavior that appears to result from overconfidence may often also have rational, Bayesian interpretations (Benoît and Dubra 2011; Manso 2013; Van den Steen 2004). For example, assessing yourself to be above average is only a bias for those below the average, which may be a small proportion of the population. In addition, if your knowledge about the performance of your comparison group is low, it may make sense to place yourself above it.

\section{Nonpecuniary Benefits}

The above interpretations primarily address the observation of too much entry by entrepreneurs. As we note earlier, there is also mounting evidence of persistence in entrepreneurship despite the low average returns from entrepreneurial effort discussed earlier and the availability of more attractive alternative occupations. Hence, if misperceptions of success probabilities drive entrepreneurship, why aren't such initial misperceptions corrected by experience?

One parsimonious interpretation for both entry and persistence in entrepreneurship is the possibility that entrepreneurs receive nonpecuniary benefits from their self-employment. When authors like Hamilton (2000) and Moskowitz and 
Vissing-Jørgensen (2002) point out the low average returns for entrepreneurship, as discussed earlier in this paper, they also advance the possibility that nonstandard preferences for autonomy and control could be potential explanations for individuals' inclination to become entrepreneurs as well as their persistence in entrepreneurship. Job characteristics that standard economic theories typically view as a means to obtaining higher pecuniary rewards-such as decision rights and control—may, for some people, be inherently valuable ends themselves.

People with such preferences may be lured to entrepreneurship by the promise of these job characteristics even though earnings may be lower. For instance, Frey, Benz, and Stutzer (2004) argue that independence and autonomy at work are sources of "procedural utility," which raise happiness. In their discussion of small firms in the US economy, Hurst and Pugsley (2011) point out that most start small and remain small, with no new technology and no intention of growing. Many of them are small service firms: lawyers, skilled craftsmen, real estate agents, restaurateurs, and the like. Based on survey evidence from the Panel Study of Entrepreneurial Dynamics, a nationally representative sample of 34,000 individuals during the fall of 2005 and the early winter of 2006, and the Kauffman Firm Survey, a panel study of 4,928 businesses that were newly founded in 2004, Hurst and Pugsley find that, for these firms, entrepreneurs claim nonpecuniary benefits as a first-order motive for self-employment.

However, the precise nature of these nonpecuniary benefits has remained largely unclear. For example, entrepreneurs work longer hours than the average employee. In only two of the 25 OECD countries (Russia and Chile) do the employed work longer hours than the self-employed, and the self-employed tend to work, on average, between 2 and 14 more hours (that is, 5-35 percent more) per week (Åstebro and Chen 2014). Thus, the nonpecuniary benefits do not simply reflect a preference for leisure. One possible source of nonpecuniary benefits is the autonomy and independence that an entrepreneur enjoys in allocating personal work time. More broadly, an entrepreneur can exercise control over the company and need not worry about interference by other parties. The importance of factors such as "control over one's life" and a "sense of purpose" is documented in studies that are not focused on entrepreneurship but instead study hypothetical choices in relation to predicted subjective levels of happiness over varied contexts (for example, Benjamin, Heffetz, Kimball, and Rees-Jones 2012). Other nonpecuniary benefits from self-employment may arise from the pride in bringing one's own business idea to market success or from a taste for variety. Addressing the latter case, Åstebro and Thompson (2011) surveyed 820 Canadian entrepreneurs who sought assistance at the Canadian Innovation Center at the University of Waterloo and compared their responses to those of a matched sample of 300 Canadian non-entrepreneurs. They find that those who have been entrepreneurs tend to be those whose reported behavior suggests a taste for variety, for instance they have varied labor market experience.

There have been attempts to infer the nonpecuniary benefits from self-employment; typically, this involves looking at the lower average returns 
earned by entrepreneurs, adjusting for other factors, and then noting that the nonpecuniary benefits must be large enough to offset this difference. Thus, as we note earlier, Hamilton (2000) estimates a median net present value lifetime earnings differential of 35 percent for individuals in business for ten years. Moskowitz and Vissing-Jørgensen (2002) find that nonpecuniary benefits of self-employment may be as large as 143 percent of total annual income. Åstebro and Thompson (2011) find the size of the nonpecuniary benefits of having a large variety of skills in entrepreneurship is on the order of 16 to 22 percent of annual household income.

Obviously, it is almost impossible to infer the nature and magnitude of these nonpecuniary benefits directly from these data. Usually, these benefits are private, and the measured earnings differentials can only provide a crude approximation. Experimental studies thus provide useful complementary evidence in this regard. While such studies are usually restricted to the study of non-entrepreneurial samples and the situations under consideration are rather artificial, they can advance our understanding of these nonpecuniary motives by demonstrating a preference for keeping control over decisions, shedding light on the motivations underlying this behavior and highlighting their potential importance for understanding entrepreneurship.

For example, Cooper and Saral (2013) ran experiments with 184 subjects-a mixture of undergraduates, business school students, entrepreneurs, and other business people-who performed the task of answering questions from the Graduate Management Aptitude Test (GMAT). In the study, subjects decided whether to work alone or in groups. Entrepreneurs showed a greater willingness to pay for working independently, despite monetary incentives to the contrary. In a post-experimental questionnaire, many subjects who revealed a preference for working alone indicated a fear of loss of control or a preference for self-reliance.

Other recent experiments look at the underlying motivations that lead individuals to cede or retain control. Fehr, Herz, and Wilkening (2013) study a structured interaction in which principals must decide whether to delegate decision rights to agents in a situation of incomplete information. Using a subject pool of 504 university students in Zurich, they conducted a laboratory experiment showing that individuals hold on to decision rights in situations in which rendering control would clearly be preferable for all involved parties in terms of expected monetary value. This behavior does not diminish with experience, and appears to be driven by regret aversion: if subjects delegate decision rights but discover later that they would have been better off keeping them, they display strong negative reactions. Owens, Grossman, and Fackler (forthcoming) provide further experimental evidence for inefficient holding on to control. In their study, subjects must choose between an asset that will pay off if they answer a question correctly or an asset that will pay off if their partner answers a question correctly. Results over 108 students show that individuals are willing to sacrifice 8 to 15 percent of expected earnings in exchange for control over their payoff. Similar considerations regarding an inherent value of authority and control may drive an entrepreneur's decision to remain in entrepreneurship even when doing so is unprofitable from a material perspective. 
Finally, Bartling, Fehr, and Herz (forthcoming) conducted an experiment that measures individuals' intrinsic valuation of decision rights. Subjects participate in a game in which a principal or an agent can make decisions that have monetary consequences for both. Principals reveal indifference between their own decision and a specific decision by the agent, and these decisions define two lotteries. If decision rights carry no intrinsic value, the certainty equivalents of both lotteries must be the same. This is tested by again presenting the lotteries to the principals but simply as given lotteries over outcomes that are not the result of anyone's decision. Differences in elicited certainty equivalents would therefore reflect the direct impact of decision rights on utility. In a group of 172 students at the University of Zurich, Bartling, Fehr, and Herz identify an average compensating differential of 16.7 percent for letting the agent decide. Hence, unlike with evidence from the field, where the inferred compensating differentials for entrepreneurship may include many components, in this experimental study, a precise value is given to one specific dimension: personal control over decision making.

Taken together, evidence from the field-specifically, the observed compensating differentials and the complementary survey evidence-strongly suggest that nonpecuniary benefits may play an important role in the decision to become and remain an entrepreneur. Experimental evidence, which allows studying the determinants of human behavior more directly, also highlights mechanisms that may underlie such nonpecuniary benefits of entrepreneurship. Entrepreneurs may be those who like to work independently and not rely on others, and control appears to be inherently valuable.

However, while the evidence above suggests an important role for nonpecuniary utility from entrepreneurial activity, our view of the literature is that a gap remains in identifying the importance of these considerations for explaining the entry and persistence puzzle. Much more needs to be understood about the importance and precise nature of nonpecuniary factors for driving entrepreneurship. For example, the evidence by Hurst and Pugsley (2011) indicates that individuals primarily motivated by nonpecuniary factors do not necessarily sort into high-growth sectors and, instead, are satisfied by consuming desirable job characteristics in low-growth sectors. This suggests that preferences for autonomy and control may not only drive the decision to become an entrepreneur but also the kinds of businesses that entrepreneurs pursue. The relevance of nonpecuniary benefits in explaining entrepreneurship in different sectors of the economy is, therefore, a promising possible interpretation but one for which more research is necessary.

\section{New Frontiers in Behavioral Entrepreneurship}

Clearly, behavioral interpretations of the drivers of entrepreneurship are potentially valuable in accounting for the entry and persistence puzzle. However, none of the interpretations stands out as the primary factor, and there is little evidence on how much of the behavior of actual entrepreneurs is accounted for by any of the 
mechanisms. There is plenty of circumstantial evidence for each of the possible explanations, but no "smoking gun." Indeed, reviewing the evidence on the roots of entrepreneurship, what surprises us most is how little we really know.

In this regard, it is important that research continue to pursue an understanding of the role the above mechanisms, as well as others, play in entrepreneurship. Indeed, research on the behavioral roots of entrepreneurship is proceeding on many fronts. To conclude this article, we lay out three directions that seem especially promising and important.

First, much of the research on entry into entrepreneurship has tended to focus on single factors-such as risk preferences, overconfidence, or nonpecuniary benefits. The time is ripe to compare and contrast these factors since the evidence is often consistent with multiple candidate explanations. For example, the data show that the relationship between personal wealth and entrepreneurship is flat for most of the wealth distribution but rises sharply above the 80 th percentile of wealth and is steepest for the wealthiest 5 percent of the population (Hurst and Lusardi 2004). Such evidence is consistent with risk preferences as a driving factor for entry-risk aversion may be decreasing in wealth-but it is also consistent with entrepreneurship being a luxury good that is consumed more by wealthier individuals. Of course, it is also consistent with the presence of financing constraints in entrepreneurshipagain, highlighting the necessary caution that must accompany any interpretation of this fact.

Research into the roots of entrepreneurship could also benefit from richer data that allows disentangling different interpretations. For example, to differentiate preference-based explanations from overconfidence and optimism, valuable insights might be gained from a detailed panel study comparing entrepreneurs' assessments of and motivations for becoming entrepreneurs both before they begin and afterwards. Do they regret their entry decision? Such surveys may suffer from after-the-fact justifications of own choices and from hindsight bias but can nonetheless shed further light on the relevance of the different factors in driving entry into entrepreneurship.

Progress on quantifying the relevance of the candidate explanations also requires reliable and precise measurements so that research can cumulatively build towards a consensus. Currently, the most precise measurements often take place in laboratory settings, implicitly assuming that more general measures of optimism, overconfidence, and preferences are stable and generalizable across contexts. Identification that is directly linked to entrepreneurial activity is likely to yield more insight into the mechanisms driving entry. Furthermore, just as many factors may account for the puzzle we outline, it also seems conceivable that different factors may account for various sub-segments of entrepreneurship. While small business owners may mainly be motivated by nonpecuniary benefits, entrepreneurship at the technological frontier may be better explained by overconfidence or risk preferences. Understanding such heterogeneous motivations, where they apply, and how they may interact seems critically important for understanding entrepreneurial entry and persistence. 
Second, it is important to understand how individuals' perceptions of entrepreneurship are formed and shaped. Optimism, overplacement, and overestimation manifest themselves in exaggerated beliefs about the profitability of entrepreneurial activity. Such beliefs about the returns to entrepreneurship may be shaped by social context, including role models or peers. For example, there appears to be intergenerational correlation in entrepreneurship and self-employment (Dunn and Holtz-Eakin 2000). Lindquist, Sol, and van Praag (forthcoming) show, using data from biological children and adoptees, that nonbiological factors as well as biological factors indeed contribute to this association but that post-birth factors play a more important role. Using census data from Denmark, Nanda and Sørensen (2010) provide further evidence on the relevance of social factors, finding that individuals are more likely to become entrepreneurs if their coworkers have previously been entrepreneurs (see also Giannetti and Simonov 2009). Lerner and Malmendier (2013) also find that peers shape entry, but their evidence is that of reduced entry into entrepreneurship among MBA students whose peers had entrepreneurial experience. In addition, Lerner and Malmendier find that having entrepreneurial peers reduces the likelihood of starting firms that fail. This latter work suggests that it may be possible to reduce potential distortions in the expected distribution of the returns to entrepreneurship through exposure to those who have experienced it first-hand. Preference-based explanations may also have their root in an individual's social environment. For instance, persistence in entrepreneurship may be influenced by different cultural perceptions of the stigma of failure.

Finally, the societal implications of "excessive entry" need to be better understood. There is a widely held belief that some entrepreneurs generate substantial positive externalities, and excessive entry may be central to the process of creative destruction. For example, it has been estimated that probably well in excess of 90 percent of the benefits of breakthrough innovation go to society as a whole rather than to the individual inventor, their partners, or their financial backers (Baumol 2002; Nordhaus 2004). In this sense, perhaps excessive entry is a blessing for society. Understanding whether excessive entry is in fact welfare enhancing due to these externalities is therefore important for guiding policy. Some initial steps in understanding the interplay of behavioral biases and welfare have been made by Bernardo and Welch (2001), who use an evolutionary model to show equilibrium persistence of overconfident entrepreneurs. They assume that overconfident entrepreneurs have too much confidence in their private information-that is, they suffer from overprecision-and are therefore less likely to imitate their peers. While such overconfidence is harmful to the overconfident entrepreneurs, Bernardo and Welch show that it can be welfare enhancing for society.

Whether excessive entry is indeed optimal from a societal perspective may critically depend on the actual drivers of entry and the sector in which excess entry takes place. For example, while overestimation and optimism may trigger the pursuit of breakthrough innovations with strong positive externalities, overplacement may primarily lead to entry into already contested markets, and it may be associated more with imitation. Hence, while overplacement may still indirectly foster 
innovation through increased competition within a market, the potential positive externalities are much less clear.

Similarly, entrepreneurs with strong nonpecuniary motivations may mainly sort into low-growth, non-inventive small businesses. Consequently, policies subsidizing entrepreneurship must be examined to determine the extent to which they provide positive externalities for the economy as opposed to only providing consumption value to the entrepreneur. Policies that simply favor small businesses, which are common in the US and other countries, may not be optimal from a societal viewpoint (Hurst and Pugsley 2011). In particular, the potential prevalence of nonpecuniary benefits as the main driver into small-scale entrepreneurship may call for stricter targeting of policy to foster high-growth industries at the technological frontier.

A comprehensive account of entrepreneurial decision making is likely to include both behavioral and nonbehavioral elements. In our view, behavioral research has not yet provided definitive explanations for puzzling aspects of entrepreneurship. Rather, the real promise of behavioral research lies in the potential for future insights that integrate and enlighten our understanding of this important dimension of economic activity.

- We thank David Autor, Chang Tai Hsieh, Ulrike Malmendier, and Timothy Taylor for editorial guidance. Åtebro acknowledges financial support from the HEC Foundation. Herz acknowledges financial support from the European Research Council grant on the Foundations of Economic Preferences. Nanda thanks Jesper B. Sørensen, Niels Westergård-Nielsen, Arhus University, and Statistics Denmark for providing access to the Danish microdata and the Kauffman Foundation and the Division of Research and Faculty Development at Harvard Business School for financial support. Weber is very grateful to Steven Klepper for several discussions that helped shape some of the arguments in this article. This paper has used microdata from the Integrated Database for Labor Market Research in Denmark. Figure 2 has been screened to ensure no confidential data are revealed.

\section{References}

Ahn, Taehyun. 2010. "Attitudes toward Risk and Self-employment of Young Workers." Labour Economics 17(2): 434-442.

Åstebro, Thomas. 2003. "The Return to Independent Invention: Evidence of Risk Seeking, Extreme Optimism or Skewness-Loving?" Economic Journal 113(484): 226-39.

Åstebro, Thomas, and Jing Chen. 2014. "The
Entrepreneurial Earnings Puzzle: Mismeasurement or Real?" Journal of Business Venturing 29(1): 88-105.

Åstebro, Thomas, Scott A. Jeffrey, and Gordon Adomdza. 2007. "Inventor Perseverance after Being Told to Quit: The Role of Cognitive Biases." Journal of Behavioral Decision Making 20(3): 253-72. 
Åstebro, Thomas, José Mata, and Luís SantosPinto. 2014. "Skewness Seeking: Risk Loving, Optimism or Overweighting of Small Probabilities?" Theory and Decision. Published online January 29.

Åstebro Thomas, and Peter Thompson. 2011. "Entrepreneurs: Jacks of all Trades or Hobos?" Research Policy 40(5): 637-49.

Bartling, Björn, Ernst Fehr, and Holger Herz. Forthcoming. "The Intrinsic Value of Decision Rights." Econometrica.

Baumol, William. 2002. The Free-Market Innovation Machine: Analyzing the Growth Miracle of Capitalism, p. 133-35. Princeton University Press.

-Benjamin, Daniel J., Ori Heffetz, Miles S. Kimball, and Alex Rees-Jones. 2012. "What Do You Think Would Make You Happier? What Do You Think You Would Choose?" American Economic Review 102(5): 2083-2110.

Bengtsson, Ola, and Daniel Ekeblom. 2014. "The Bright but Right View? A New Type of Evidence on Entrepreneurial Optimism." IFN Working Paper 1008, February 19.

-Benoît, Jean Pierre P., and Juan Dubra. 2011. "Apparent Overconfidence." Econometrica 79(5): 1591-1625.

Bernardo, Antonio E., and Ivo Welch. 2001. "On the Evolution of Overconfidence and Entrepreneurs." Journal of Economics $\mathcal{E}$ Management Strategy 10(3): 301-30.

Camerer, Colin, and Dan Lovallo. 1999. "Overconfidence and Excess Entry: An Experimental Approach." American Economic Review 89(1): 306-18.

Cooper, Arnold C., Carolyn Y. Woo, and William C. Dunkelberg. 1988. "Entrepreneurs' Perceived Chances for Success." Journal of Business Venturing 3(2): 97-108.

Cooper, David J., and Krista Jabs Saral. 2013. "Entrepreneurship and Team Participation: An Experimental Study." European Economic Review 59(C): 126-40.

Cramer, J. S., J. Hartog, N. Jonker, and C. M. Van Praag. 2002. "Low Risk Aversion Encourages the Choice for Entrepreneurship: An Empirical Test of a Truism." Journal of Economic Behavior E Organization 48(1): 29-36.

Dawson, Christopher, David de Meza, Andrew Henley, and G. Reza Arabsheibani. 2014. "The Power of Non-Positive Thinking: Self-Employed Optimists Earn Less than Self-Employed Realists." Unpublished paper, University of Bath.

De Meza, David, and Clive Southey. 1996. "The Borrower's Curse: Optimism, Finance and Entrepreneurship." Economic Journal 106(435): 375-86.

Dunn, Thomas, and Douglas Holtz-Eakin. 2000. "Financial Capital, Human Capital, and the Transition to Self-Employment: Evidence from Intergenerational Links." Journal of Labor Economics 18(2): 282-305.

Ederer, Florian, and Gustavo Manso. 2013. "Is Pay for Performance Detrimental to Innovation?" Management Science 59(7): 1496-1513.

Fehr, Ernst, Holger Herz, and Tom Wilkening. 2013. "The Lure of Authority: Motivation and Incentive Effects of Power." American Economic Review 103(4): 1325-59.

Frey, Bruno S., Matthias Benz, and Alois Stutzer. 2004. "Introducing Procedural Utility: Not Only What, But Also How Matters.” Journal of Institutional and Theoretical Economics 160(3): 377-401.

Giannetti, Mariassunta, and Andrei Simonov. 2009. "Social Interactions and Entrepreneurial Activity." Journal of Economics \& Management Strategy 18(3): 665-709.

Hall, Robert E., and Susan E. Woodward. 2010. "The Burden of the Nondiversifiable Risk of Entrepreneurship." American Economic Review 100(3): 1163-94.

-Hamilton, Barton H. 2000. "Does Entrepreneurship Pay? An Empirical Analysis of the Returns to Self-Employment." Journal of Political Economy 108(3): 604-31.

Harrington, Michael. 2010. "Are You a Pirate." Techcrunch, Oct. 31. http://techcrunch .com/2010/10/31/are-you-a-pirate.

Herz, Holger, Daniel Schunk, and Christian Zehnder. 2014. "How Do Judgmental Overconfidence and Over-Optimism Shape Innovative Behavior?" Games and Economic Behavior 83: 1-23.

-Hey, John Denis. 1984. "The Economics of Optimism and Pessimism." Kyklos 37(2): 181-205.

Holm, Hakan J., Sonja Opper, and Victor Nee.

2013. "Entrepreneurs under Uncertainty: An Economic Experiment in China." Management Science 59(7): 1671-87.

-Holt, Charles A., and Susan K. Laury. 2002. "Risk Aversion and Incentive Effects." American Economic Review 92(5): 1644-55.

-Hurst, Erik, and Annamaria Lusardi. 2004. "Liquidity Constraints, Household Wealth, and Entrepreneurship." Journal of Political Economy 112(2): 319-47.

Hurst, Eric, and Benjamin Pugsley. 2011. "What Do Small Businesses Do?" Brookings Papers on Economic Activity 43(2): 73-142.

-Hvide, Hans K., and Georgios A. Panos. 2014. "Risk Tolerance and Entrepreneurship." Journal of Financial Economics 111(1): 200-23.

Jovanovic, Boyan. 1982. "Selection and the Evolution of Industry." Econometrica 50 (3): 649-70.

-Kerr, William R., and Ramana Nanda. 2010. "Banking Deregulations, Financing Constraints and Firm Entry Size." Journal of the European Economic Association 8(2-3): 582-93. 
Kihlstrom, Richard E., and Jean-Jacques Laffont. 1979. "A General Equilibrium Entrepreneurial Theory of Firm Formation based on Risk Aversion." Journal of Political Economy 87(4): 719-48.

Knight, Frank H. 1921. Risk, Uncertainty, and Profit. Houghton Mifflin, Boston.

- Landier, Augustin, and David Thesmar. 2009. "Financial Contracting with Optimistic Entrepreneurs." Review of Financial Studies 22(1): 117-50.

-Lerner, Josh, and Ulrike Malmendier. 2013. "With a Little Help from My (Random) Friends: Success and Failure in Post-Business School Entrepreneurship." Review of Financial Studies 26(10): 2411-52.

Lichtenstein, Sarah, Baruch Fischhoff, and Lawrence D. Phillips. 1982. "Calibration of Probabilities: The State of the Art to 1980.” In Judgement under Uncertainty: Heuristics and Biases, edited by D. Kahneman, P. Slovic, \& A. Tversky, pp. 306-34. Cambridge University Press.

Lindquist, Matthew J., Joeri Sol, and Mirjam van Praag. Forthcoming. "Why Do Entrepreneurial Parents Have Entrepreneurial Children?" Journal of Labor Economics.

Malmendier, Ulrike, and Geoffrey Tate. 2005a. "CEO Overconfidence and Corporate Investment." Journal of Finance 60(6): 2661-2700.

Malmendier, Ulrike, and Geoffrey Tate. 2005b. "Does Overconfidence Affect Corporate Investment? CEO Overconfidence Measures Revisited." European Financial Management 11(5): 649-59.

Manso, Gustavo. 2013. "Experimentation and the Returns to Entrepreneurship." Unpublished paper.

Moore, Don A., and Paul J. Healy. 2008. "The Trouble with Overconfidence." Psychological Review 115(2): 502-17.
Moskowitz, Tobias J., and Annette VissingJørgensen. 2002. "The Returns to Entrepreneurial Investment: A Private Equity Premium Puzzle?" American Economic Review 92(4): 745-78.

Nanda, Ramana, and Jesper B. Sørensen. 2010. "Workplace Peers and Entrepreneurship." Management Science 56(7): 1116-26.

Nordhaus, William D. 2004. "Schumpeterian Profits in the American Economy: Theory and Measurement." NBER Working Paper 10433.

Owens, Dave, Zachary Grossman, and Ryan Fackler. Forthcoming. "The Control Premium: A Preference for Payoff Autonomy." American Economic Journal: Microeconomics.

Parker, Simon C. 2009. The Economics of Entrepreneurship. Cambridge University Press.

-Puri, Manju, and David T. Robinson. 2007. "Optimism and Economic Choice." Journal of Financial Economics 86(1): 71-99.

Shane, Scott A. 2009. Fool's Gold? The Truth Behind Angel Investing in America. Oxford University Press.

Smith, Adam. 1776 [1904]. An Inquiry into the Nature and Causes of the Wealth of Nations. Edited by Edwin Cannan. London: Methuen \& Co.

Surowiecki, James. 2014. "Epic Fails of the Startup World." New Yorker, May 19. http:// www.newyorker.com/talk/financial/2014/05 /19/140519ta_talk_surowiecki.

-Van den Steen, Eric. 2004. "Rational Overoptimism (and Other Biases)." American Economic Review 94(4): 1141-51.

Wasserman, Noam. 2008. "The Founder's Dilemma." Harvard Business Review, February, 103-109.

Weinstein, Neil D. 1980. "Unrealistic Optimism about Future Life Events.” Journal of Personality and Social Psychology 39(5): 806-820. 
70 Journal of Economic Perspectives 